\title{
Rho-dependent cell spreading activated by E.coli cytotoxic necrotizing factor 1 hinders apoptosis in epithelial cells
}

\author{
Carla Fiorentini $^{1,3}$, Paola Matarrese ${ }^{1}$, Elisabetta Straface ${ }^{1}$, \\ Loredana Falzano ${ }^{1}$, Gianfranco Donelli ${ }^{1}$, Patrice Boquet ${ }^{2}$ and \\ Walter Malorni ${ }^{1}$ \\ ${ }^{1}$ Department of Ultrastructures, Istituto Superiore di Sanità, Viale Regina Elena \\ 299, 00161 Rome, Italy \\ 2 INSERM U452 Faculté de Médecine, Avenue de Valombrose, 06107, Nice \\ Cedex 2, France \\ ${ }^{3}$ corresponding author: Carla Fiorentini, tel: +39 6-49902905; \\ fax: +39 6-49387140; e-mail: fiorentini@ul.net.iss.it
}

Received 9.2.98; revised 15.5.98; accepted 2.6.98

Edited by R.A. Knight

\begin{abstract}
Cell-cell and cell-matrix interactions play a pivotal role in numerous cell functions including cell survival and death. In this work, we report evidence that the Rho-dependent cell spreading activated by a protein toxin from $E$. coli, the cytotoxic necrotizing factor 1 (CNF1), is capable of hindering apoptosis in HEp-2 cells. In addition to the promotion of cell spreading, CNF1 protects cells from the experimentallyinduced rounding up and detachment and improves the ability of cells to adhere to each other and to the extracellular matrix by modulating the expression of proteins related to cell adhesion. In particular, the expression of integrins such as $\alpha_{5}$, $\alpha_{6}$ and $\alpha_{v}$, as well as of some heterotypic and homotypic adhesion-related proteins such as the Focal Adhesion Kinase, E-cadherin, $\alpha$ and $\beta$ catenins were significantly increased in cells exposed to CNF1. Our results suggest, however, that the promotion of Rho-dependent cell spreading is the key mechanism in protecting cells against apoptosis rather than cell adhesion per se. A toxin inducing cell spreading without activating Rho, such as Cytochalasin B, was in fact ineffective in favouring cell survival. These data are of relevance (i) for the understanding of the role of the actin-dependent and especially Rho-dependent cellular activities involved in apoptosis regulation and (ii) in providing some clues to understanding the mechanisms by which bacteria, by controlling cell fate, might exert their pathogenic activity.
\end{abstract}

Keywords: apoptosis; CNF1; actin cytoskeleton; cell adhesion; cell spreading; Rho

Abbreviations: CNF1, cytotoxic necrotizing factor 1; $\mathrm{CB}$, cytochalasin B; FCS, fetal calf serum; PBS, phosphate buffered saline; BSA, bovine serum albumin; BrdU, bromodeoxyuridine; FAK, focal adhesion kinase; MAP, mitogen-activated protein

\section{Introduction}

Apoptosis is a physiological form of cell death which plays an important role in tissue development and homeostasis, maintaining a correct cell number in the body by balancing cell growth and death (Martins and Earnshow, 1997). It is a multi-phase process characterized by three distinct steps: in the first cells receive the death stimulus, in the second the cell is triggered to undergo apoptosis (effector phase) and, during the last step, typical irreversible morphological and molecular markers of apoptosis can be detected (Kroemer, 1997). Without apoptosis, detached cells from endothelia or epithelia could possibly reattach to inappropriately sited matrices, including the matrix that they would eventually synthesize themselves, and resume growth (Ruoslahti and Reed, 1994). Apoptosis occurring in detached cells would abrogate this escape mechanism. In addition, it is now established that cells forced to extend themselves over a large surface (spreading cells) survive better and proliferate faster than cells with a more rounded shape (Ruoslahti, 1997). Consequently, an increase in cell adhesion and spreading can protect cells against apoptosis.

Cell adhesion and cell spreading are different and welldefined phenomena mainly dependent on the integrity and function of the actin cytoskeleton in terms of focal adhesion plaque assembly or cell contractility (Burridge et al, 1997; Nobes and Hall, 1995). The actin cytoskeleton organization is controlled by proteins belonging to the Ras-like p21 Rho family (Hall, 1998) which are also involved in a number of cellular functions influencing cell fate. Among factors able to interfere with pathways leading to cell survival or death, we have very recently reported that a bacterial toxin from $E$. coli is capable of protecting epithelial cells against apoptosis (Fiorentini et al, 1997b; 1998b). The toxin, named Cytotoxic Necrotizing Factor 1 (CNF1), belongs to that protein toxin family which controls the actin cytoskeleton via modulation of regulatory G-proteins (Aktories, 1997). CNF1 permanently activates the p21 Rho protein by deamidation of glutamine 63 (Flatau et al, 1997; Schmidt et al, 1997). By activating Rho, the toxin stimulates a number of kinases in cells (Fiorentini et al, 1997a; Lacerda et al, 1997) which in turn promote actin assembly (Falzano et al, 1993; Fiorentini et al, 1995) and cell contractility (Fiorentini et al, 1997a).

In the present work, we explored the role of some Rho-dependent cell activities in hindering apoptosis. Our data clearly indicate that, rather than the augmented adhesiveness to the cell matrix, the Rho-dependent cell spreading and contractility (associated with the increase in stress fiber organization) are the factors favouring cell survival. 


\section{Results}

\section{CNF1 protects HEp-2 cells from UVB-induced apoptosis}

We have reported that UV radiation induces cytoskeletondependent surface blebbing and cell death in epithelial cells (Malorni et al, 1994; Straface et al, 1995) and that these effects are partially counteracted by drugs capable of improving cell adhesion (Malorni et al, 1995). We have thus investigated whether the promotion of actin assembly and cell spreading due to CNF1 could play a key role in the toxininduced reduction of apoptosis that we have very recently observed in epithelial cells (Fiorentini et al, 1997b; 1998b). All data herein reported refer to cells which maintained contacts with the substrate after the various treatments. We did not include the observations on detached cells floating in the culture medium because all of them, irrespective of the treatment, showed nuclear changes typical of apoptosis. Figure 1 shows the results obtained by phase contrast microscopy (Figure 1a, c, e, g) and fluorescence microscopy (Figure 1b, d, f, h). The former gives a general picture of the monolayer after each treatment, and the latter shows chromatin structure and clumping typical of apoptosis by using Hoechst 33258, a fluorescent probe which specifically binds DNA (Bursh et al, 1992). HEp-2 cells growing in

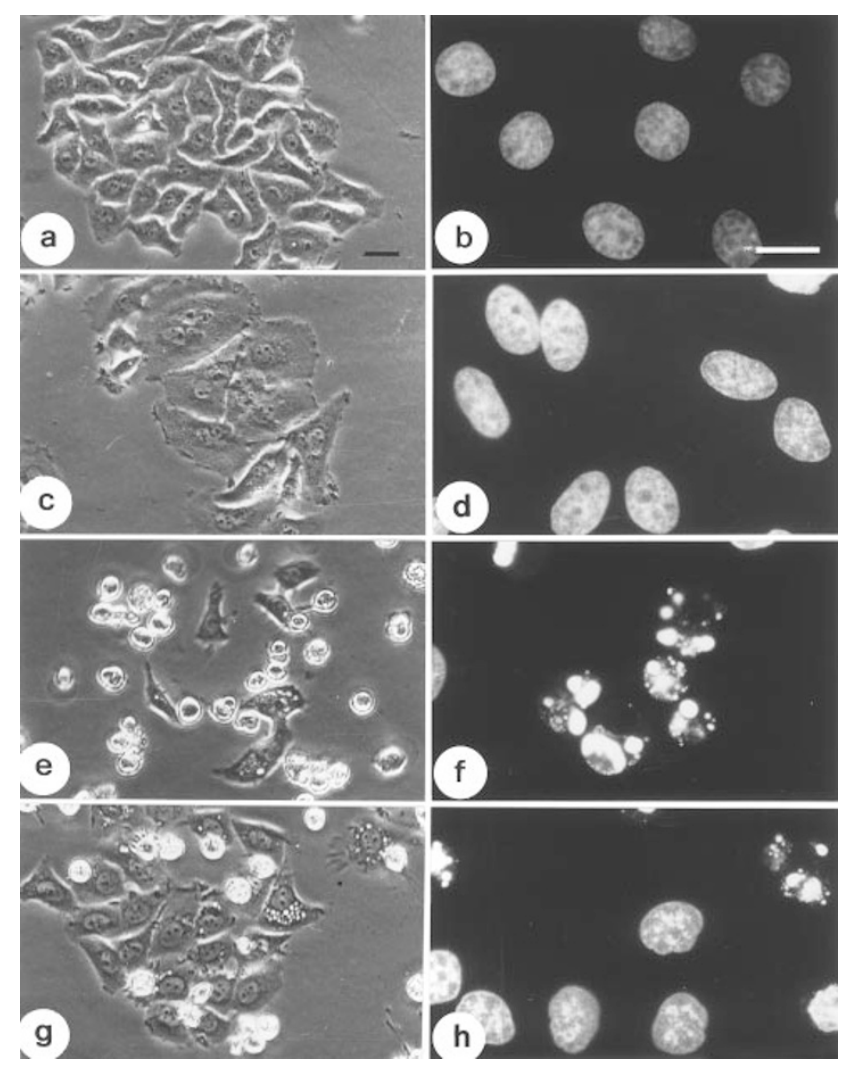

Figure 1 CNF1 treatment prevents the UVB-induced rounding up and apoptosis in HEp-2 cells. Left panel: phase contrast and right panel: fluorescence microscopy of cells stained with Hoechst 33258 . (a,b) Control cells; (c,d) cells treated for $48 \mathrm{~h}$ with CNF1; (e,f) UVB-treated cells; $(\mathbf{g}, \mathbf{h})$ cells treated for $48 \mathrm{~h}$ with CNF1 and then with UVB monolayer are polygonal-shaped (Figure 1a) with a single rounded nucleus per cell (Figure 1b). Upon exposure to CNF1, cells became large, flattened and with prominent membrane ruffles (Figure 1c). Treated cells were also multinucleated but such a modification did not interfere with chromatin organization, all the nuclei being regularly-shaped (Figure 1d).

After exposure to UVB radiation, cells maintained for $24 \mathrm{~h}$ in fresh medium underwent cell retraction, rounding, and displayed a typical sign of cell injury named surface blebbing (Figure 1e). Most cells still adhering to the substrate (about $49 \%$, as shown in Figure 2), displayed nuclei with condensed or fragmented chromatin (Figure 1f). These cells, however, easily underwent detachment since the cell-substrate adhesion was much weaker. Pretreatment with CNF1 for $48 \mathrm{~h}$ allowed cells to resist the UVBinduced effects, most cells still adhering to the substrate (Figure 1g) with normal-shaped nuclei (Figure 1h). When a quantitative and statistical analysis of these phenomena was performed on six different experiments, it became evident that the protection offered by CNF1 was highly significant $(P<0.01$, Figure 2). Noticeably, CNF1 also counteracted apoptosis when induced by stimuli other than UVB. In fact, apoptosis caused by the antineoplastic drug Etoposide (58\% of apoptosis after $48 \mathrm{~h}$ ) or by the withdrawal of growth factors (serum starvation, $28 \%$ after $48 \mathrm{~h})$ was significantly prevented when cells were preexposed to CNF1 $(\triangle=48 \%$ and $88 \%$, respectively; $P<0.01)$. In this paper, however, only data obtained by using UVB as apoptotic inducer are reported.

To rule out the possibility that CNF1-promoted multinucleation could induce a more quiescent state in the cell population thus influencing susceptibility to apoptosis, we have performed a cytofluorimetric analysis of DNA. Our results clearly indicated that multinucleation did not influence the capability of toxin-treated cells to duplicate their DNA. In fact, the percentage of cells in S phase after 24 and $48 \mathrm{~h}$ of treatment $(29.6 \%$ and $23.5 \%$, respectively)

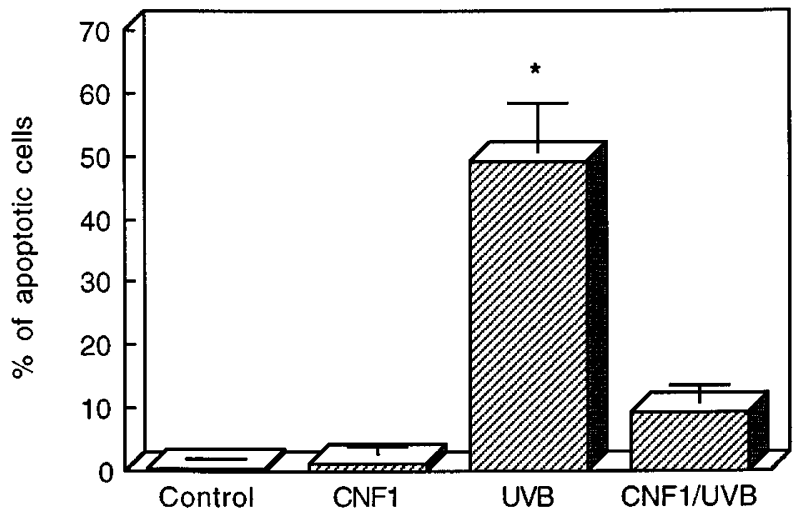

Figure 2 CNF1 significantly protects cells from UVB-induced apoptosis. Percentages of apoptotic cells after different treatments. Data refer only to cells which remained in the monolayer. It is noteworthy that CNF1 is capable of strongly decreasing the percentage of apoptosis with respect to UVB $\left({ }^{*}, P<0.01\right)$. The values are the means \pm S.D. from six separate experiments. Statistical significance was determined by Student's $t$-test 
was comparable to the percentages in control cells at the same time (23.1\% and $25.2 \%$ at 24 and $48 \mathrm{~h}$, respectively).

\section{Cell spreading promoted by CNF1 protected HEp-2 cells from the radiation-induced actin cytoskeleton changes}

Scanning electron microscopy analyses showed that, in control cells (Figure 3a), UVB exposure induced cell retraction, alterations of surface microvillous structures and the formation of small bulb-like protrusions in cells adhering to the substrate (Figure $3 \mathrm{c}$ ). In contrast, CNF1 pre-treated cells appeared to be firmly attached to the substrate (Figure $3 d$ ) and showed a CNF1-like (Figure $3 b$ ) surface ultrastructure even after exposure to UVB. In fact, the cells maintained stable cell-to-cell and cell-substrate interactions without undergoing rounding or detachment from the substrate (Figure 3d). When cells were labeled with rhodaminphalloidin for F-actin detection, the disappearance of actin organization induced by UVB (Figure $3 \mathrm{~g}$ ) was evident. On the contrary, an increase in actin stress fibers was observed in HEp-2 cells treated with CNF1 (Figure 3f) with respect to control cells (Figure $3 e$ ) and the actin disorganization induced by radiation was significantly prevented by pretreatment with CNF1 (Figure 3h).

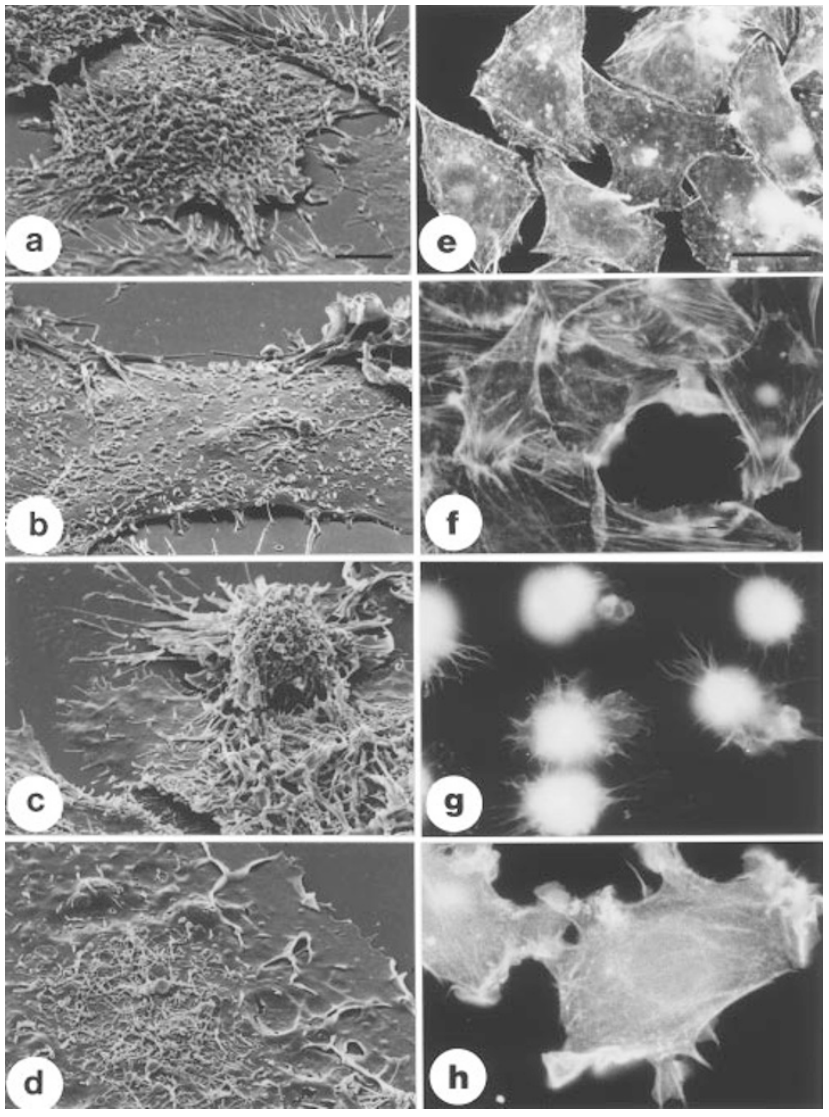

Figure 3 CNF1 treatment protects from the UVB-induced cell damage. Left panel: scanning electron micrographs and right panel: fluorescence micrographs of cells stained for F-actin detection of $(\mathbf{a}, \mathbf{e})$ control cells, $(\mathbf{b}, \mathbf{f})$ cells treated for $48 \mathrm{~h}$ with CNF1, $(\mathbf{c}, \mathbf{g})$ UVB-treated cells, $(\mathbf{d}, \mathbf{h})$ cells treated for $48 \mathrm{~h}$ with $\mathrm{CNF} 1$ and then with UVB

\section{The actin filament-disrupting agent $\mathrm{CB}$, although inducing multinucleation and cell spreading, does not protect cells against apoptosis}

We next investigated the possibility that the protective effect exerted by CNF1 on apoptosis could be related to the ability of this toxin to induce multinucleation, cell spreading and to increase the cell volume. For this purpose, we used CB, which is able, in a certain range of concentrations, to cause multinucleation, to promote cell spreading and to increase cell volume by directly interacting with the actin filaments without involving the Rho proteins (Cooper, 1987). The CB dose used in this study was $0.5 \mu \mathrm{g} / \mathrm{ml}$, i.e. the minimal toxin dose causing the formation of flattened, multinucleated cells
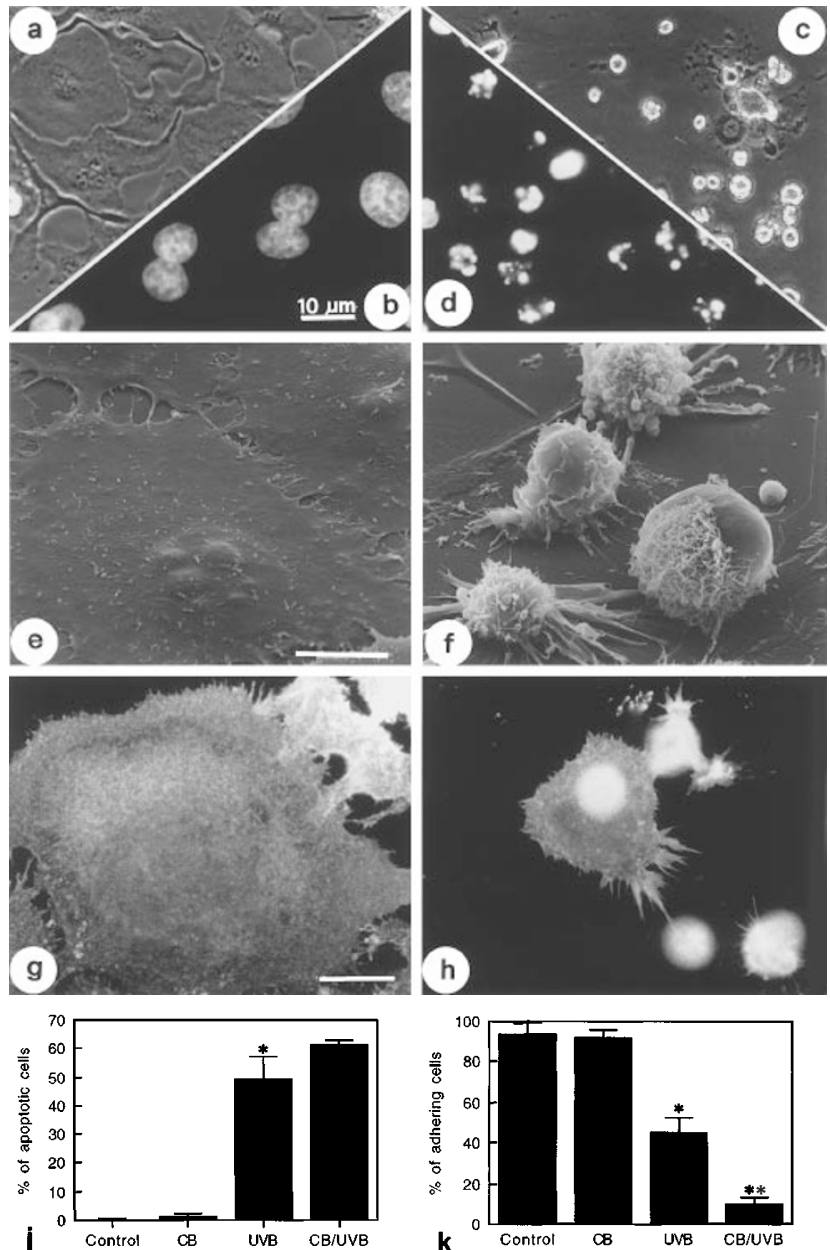

Figure $4 \mathrm{CB}$ treatment does not prevent cell retraction and apoptosis induced by UVB in HEp-2 cells. (a,c) Phase contrast, (b,d) fluorescence microscopy of cells stained with Hoechst $33258,(\mathbf{g}, \mathbf{h})$ fluorescence microscopy of cells stained for F-actin detection, and $(\mathbf{e}, \mathbf{f})$ scanning electron microscopy. Cells treated for $48 \mathrm{~h}$ with $\mathrm{CB}$ are shown in $(\mathbf{a}, \mathbf{b}, \mathbf{e}, \mathbf{g})$; cells treated $48 \mathrm{~h}$ with $\mathrm{CB}$ and then with UVB are shown in $(\mathbf{c}, \mathbf{d}, \mathbf{f}, \mathbf{h})$. (j) Percentages of apoptotic cells after different treatments. (k) Percentages of cells still adhering to the substrate after different treatments. Note that the percentage of apoptosis shown in (j) is inversely proportional to the percentage of adhering cells shown in (k). The values are the means + S.D. from four separate experiments. Statistical analysis was performed by Student's $t$-test. $\left(^{*}\right)$ in $(\mathbf{j})$ and $(\mathbf{k})$ indicates $P<0.01$ versus control and CB-treated cells. $\left(^{* *}\right)$ in (k) indicate $P<0.01$ versus UV-radiated cells 
within $48 \mathrm{~h}$. Figure 4 shows the results obtained by phase contrast (Figure 4a and c), fluorescence (Hoechst: Figure 4b and $\mathrm{d}$; FITC-phalloidin: Figure $4 \mathrm{~g}$ and $\mathrm{h}$ ) and scanning electron microscopy (Figure $4 \mathrm{e}$ and f). After exposure to $\mathrm{CB}$, HEp-2 cells became large, flattened and multinucleated (Figure 4a), with two or more nuclei regularly-shaped (Figure $4 \mathrm{~b}$ ) and devoid of stress fibers (Figure $4 \mathrm{~g}$ ). UVB radiation of CB-treated cells induced a remarkable loss of adhesion to the substrate in a number of cells which finally detached (Figure 4c). The nuclei of most adherent cells showed apoptotic features (Figure 4d), and the actin organization was completely compromised (Figure 4h). In accordance with these morphological observations, the percentage of apoptotic cells after treatment with CB/UVB was significantly increased $(61.4 \%)$ with respect to UVB-irradiated cells $(49.2 \%)$ as viewed in Figure $4 \mathrm{j}$. Interestingly, the percentage of cells undergoing apoptosis after each treatment (Figure $4 \mathrm{j}$ ) was inversely related $(P<0.01)$ to the percentage of cells which, in the same conditions, still remained adherent to the substrate (Figure 4k). In fact, the percentage of these cells was significantly decreased by pre-exposure (48 h) to CB (Figure 4k). Thus, it seems that multinucleation, cell spreading and the increase in cell volume are not per se sufficient to counteract apoptosis.

\section{CNF1 protects HEp-2 cells from the UVB-induced detachment by improving cell adhesion}

We have recently reported that the activation of Rho by CNF1 is an event clearly detectable within the first hour of treatment (Flatau et al, 1997). We have also observed, however, that most of the properties of CNF1, such as multinucleation and phagocytic behaviour, are late events which occur after more than $12-24 \mathrm{~h}$ (Falzano et al, 1993). Interestingly, the ability of toxin-exposed cells to ingest particles increases with time and is inversely related to the property of such cells to counteract apoptosis (Fiorentini et al, 1997b). In fact, as shown in Figure 5a ( $\mathbf{\Delta}$ ), the protection against apoptosis was more efficient by prolonging the time of exposure to CNF1. This finding was in agreement with the time-dependent ability of CNF1treated cells to: (i) impair the cell detachment which followed exposure to UVB (Figure 5a, $\square$ ) and (ii) increase the adhesion capabilities as measured on plastic Petri dishes, the substrate on which all the experiments herein reported were performed (Figure $5 \mathrm{~b}$ ). Thus, the improvement in cell adhesion which accompanies CNF1 activity seems to be a requisite for counteracting apoptosis. Statistical analyses of the relationships between these
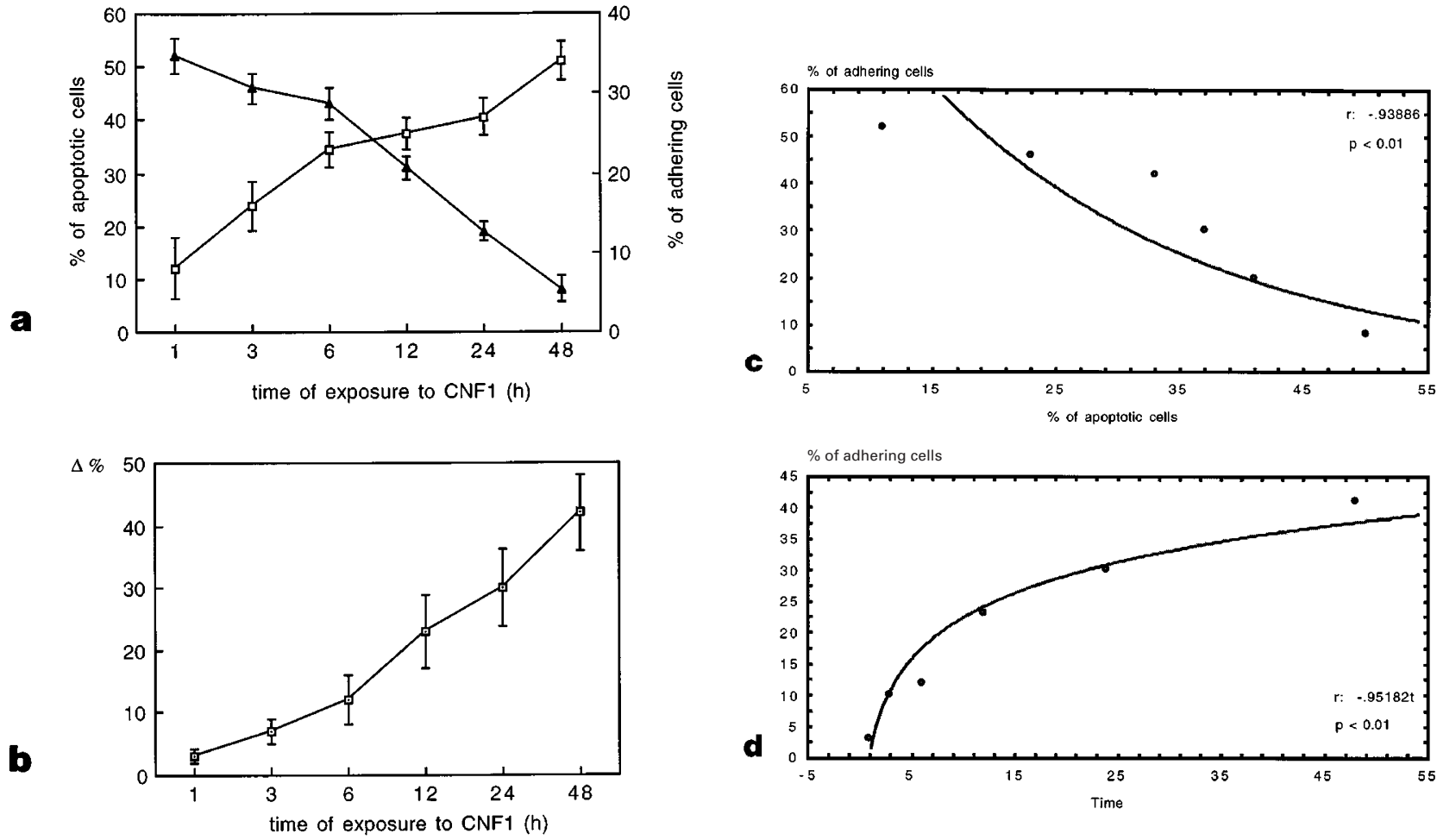

Figure 5 CNF1 protection of HEp-2 cells from UVB-induced detachment and apoptosis is a time-dependent phenomenon. (a) Percentage of apoptosis induced by irradiation $(\boldsymbol{\Delta})$ and percentage of adhering cells after UVB exposure ( $\square$ ) as a function of different times of CNF1 pre-treatment. (b) Adhesion test of HEp-2 cells after different times of exposure to CNF1 represented in $\triangle \%$ of adherent cells with respect to controls. The values are the means \pm S.D. from six separate experiments. Statistical significance determined by Student's $t$-test indicates that CNF1 significantly increases cell adhesion capability with respect to untreated cells $(P<0.01)$. Statistical analyses of these results indicated a significant inverse correlation between the percentage of apoptotic cells and that of cells adhering to the substrate (c). In addition, a significant correlation between CNF1 exposure and cell adhesion was also found (d) 
events indicated in fact a significant correlation between cell adhesion and apoptosis following increased time of exposure to CNF1 (Figure 5c, d).

\section{CNF1 modulates, in HEp-2 cells, the expression of antigens involved in cell adhesion}

We then quantitatively evaluated whether CNF1 administration could modulate the expression of some surface and cytosolic antigens related to cell adhesion. By flow cytometry we analyzed (as reported in Table 1): (i) proteins controlling cell-substrate relationships, such as the immunoglobulin-like molecule CD44 hyaluronic acid receptor), integrins such as $\alpha 1$ (collagen receptor), $\alpha 2$ (collagen receptor), $\alpha 3$ (laminin,

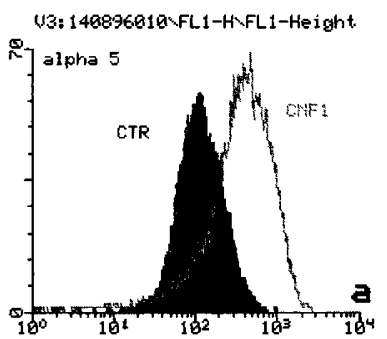
윌 alphav

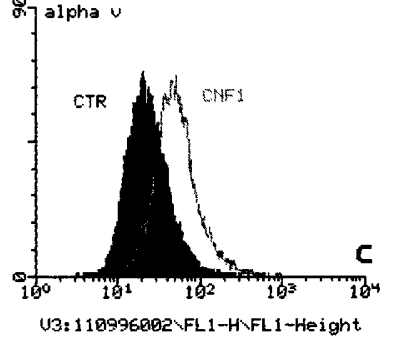

影 ICAm-1

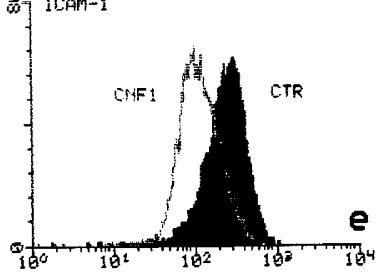

U3: $15059792 \backslash F L 1-H \times F L 1-H e i g h t$

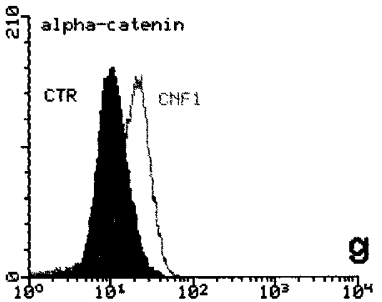

U3: 149897907 FLL1-HVLL1-Height
43: 140897964\FL1-H、FL1-Height

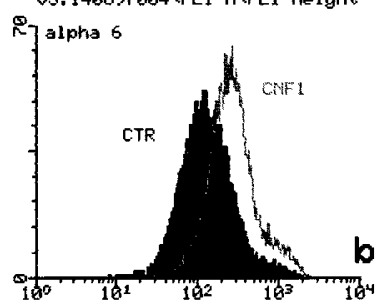

U3: 251096003 $F L 1-H$ FL1-Height

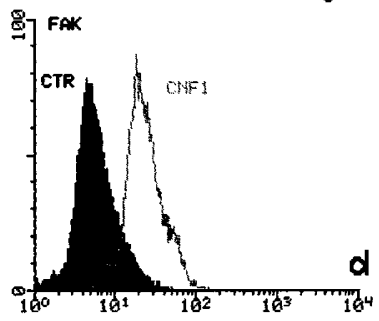

U3: 251096903\FL1-H、FL1-Height

S. E-cacherin

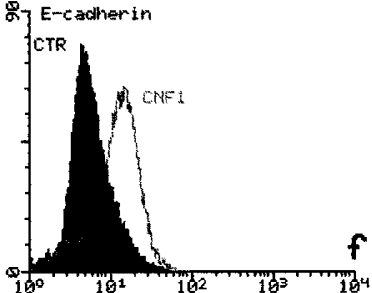

U3: 15059703\FL1-HYFL1-Height

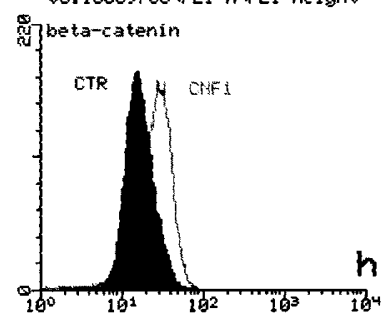

Figure 6 CNF1 provokes a change in the expression of some surface and cytosolic molecules related to cell adhesion. Histograms of flow cytometric analysis of the cell-surface or cytoplasmic molecules $\alpha 5$ (a), $\alpha 6$ (b), $\alpha \mathrm{V}$ (c), FAK (d), ICAM-1 (e), E-cadherin (f), $\alpha-(\mathbf{g})$ and $\beta$ - (h) catenin. A shift of curves indicates a decrease of ICAM- 1 and a parallel increase in $\alpha 5, \alpha 6, \alpha \mathrm{V}, \mathrm{FAK}, \mathrm{E}$ cadherin, $\alpha$-catenin and $\beta$-catenin expression after exposure to CNF1 for $48 \mathrm{~h}$. On the abscissa, FL1 indicates green fluorescence (log. scale), the ordinate indicates the relative cell number. One experiment representative of six is shown
Table 1 Quantitative evaluation of the expression, detected by flow cytometry, of surface and cytosolic antigens related to cell adhesion

\begin{tabular}{lccc}
\hline $\begin{array}{l}\text { Antigens related to cell } \\
\text { adhesion }\end{array}$ & Control & CNF1 & $\Delta \%$ \\
\hline ICAM-1 (s) & 513 & 415 & -20 \\
E-cadherin (c) $^{\star *}$ & 186 & 283 & +52 \\
$\alpha$-catenin (c) & 258 & 345 & +33 \\
$\beta$-catenin (c)* & 309 & 385 & +24 \\
FAK (c)** & 172 & 255 & +48 \\
CD44 (s) & 693 & 684 & -2 \\
$\alpha 1(\mathrm{~s})$ & 461 & 449 & -3 \\
$\alpha 2(\mathrm{~s})$ & 451 & 437 & -3 \\
$\alpha 3(\mathrm{~s})$ & 617 & 625 & +1 \\
$\alpha 4(\mathrm{~s})$ & 145 & 151 & +4 \\
$\alpha 5(\mathrm{~s})^{*}$ & 527 & 682 & +36 \\
$\alpha 6(\mathrm{~s})^{*}$ & 520 & 624 & +20 \\
$\alpha \mathrm{V}(\mathrm{s})^{*}$ & 332 & 449 & +35 \\
\hline
\end{tabular}

Calculation of fluorescence was carried out after conversion of logarithmically amplified signals into values on a linear scale and expressed as median values. (s) and (c) indicate cell surface and cytosolic labeling, respectively. *indicates a $P<0.003$; **indicates a $P<0.001$ (calculated by using K/S test)

collagen and fibronectin receptor), $\alpha 4$ (fibronectin receptor), $\alpha 5$ (fibronectin receptor), $\alpha 6$ (laminin receptor), $\alpha \mathrm{v}$ (vitronectin, fibronectin and collagen I receptor) and the adhesion plaquerelated molecule FAK; and (ii) proteins involved in cell-cell contacts, such as ICAM-1, E-cadherin, $\alpha$-catenin and $\beta$ catenin. No significant quantitative alterations of CD44, $\alpha 1, \alpha 2$, $\alpha 3$ and $\alpha 4$ were detectable by FACS analyses. However, $48 \mathrm{~h}$ of exposure to CNF1 caused a significant $(P<0.01)$ decrease $(20 \%)$ of ICAM-1 and a parallel increase in $\alpha 5(36 \%), \alpha 6$ $(20 \%), \alpha \mathrm{V}(35 \%)$, FAK (48\%), E-cadherin (52\%), $\alpha$-catenin $(33 \%)$ and $\beta$-catenin expression (24\%) (Table 1 and Figure 6$)$ Thus, both cell-cell and cell-substrate interactions can be modulated by CNF1 and these changes are probably involved in the toxin-induced mechanisms preventing apoptosis.

\section{CB does not influence the expression of antigens involved in cell adhesion in HEp-2 cells}

We analyzed the quantitative expression of some surface and cytosolic antigens related to cell-cell and cell-substrate relationships after $48 \mathrm{~h}$ of $\mathrm{CB}$ treatment. In particular, we performed this analysis comparing the median values of the histograms relative to control and CB-treated cells. No significant quantitative alterations of $\alpha 5$ (control: 427 ; $\mathrm{CB}$ : 431), $\alpha 6$ (control: 537; CB: 520), $\alpha$ v (control: 345; CB: 347), FAK (control: 320; CB: 340); ICAM-1 (control: 499; CB: 501); E-cadherin (control: 210; CB: 209); $\alpha$-catenin (control: 261; CB: 259); $\beta$-catenin (control: 304; CB: 309) were detectable by FACS

\section{Discussion}

The importance of cell adhesion processes in the induction of apoptosis has recently been underlined by several authors (Meredith and Schwartz, 1997). For instance, those cell types which require attachment to a substrate in order to grow undergo apoptosis when detached from the substrate (or when attachment is prevented) (Guadagno et al, 1993, Meredith et al, 1993). This type of apoptosis due to a 
'homeless' condition has been called 'anoikia' (from greek $\alpha \mathrm{V} \alpha$ (without) $\omega \lambda \kappa \lambda \alpha$ (home); Frisch and Francis, 1994; Frisch, 1997). Our work may add new insights in this field dealing with the promotion of cell spreading by a toxin-driven Rhodependent mechanism which significantly protects epithelial cells against apoptosis.

In order to adhere to a substrate or to other cells in a monolayer, a cell needs the active involvement of several proteins which form organized complexes, i.e. adhesion plaques and intercellular junctions. Such protein complexes are in turn linked to the cytoskeleton network, in particular to the actin microfilament system (Yamada and Geiger, 1997). For instance, establishment of cadherin-dependent cell-cell contacts requires the activity of the small GTPases Rho and Rac (Braga et al, 1997). The augmented expression, in cells exposed to CNF1, of E-cadherin as well as of $\alpha$-catenin and $\beta$-catenin, all proteins controlling in different ways the interactions between cells (Huber et al, 1996), suggests a role played by these molecules in hindering apoptosis. This is consistent with the observation that the Rho-independent effects of $C B$ in cells did not provoke the overexpression of such molecules, CB-treated cells undergoing apoptosis at a significantly higher percentage than control cells. The importance of cell-cell adhesion in favouring cell survival has been previously reported, for example, in intestinal cells forced to detach by a bacterial toxin known to perturb the actin cytoskeleton (Mahida et al, 1996). Such cells, however, although in suspension, remained alive while linked to each other.

To date, however, the majority of studies on apoptosis and cell adhesion have been focused on those mechanisms which control the interaction between a cell and the extracellular matrix (ECM). Cell-substrate relationships could be considered as composed by at least two different processes: a 'static' one (cell attachment) and a 'dynamic' one (cell spreading). The cooperation between them leads to the cell 'homing' process, which was suggested by Frisch and Francis (1994) to be a complex regulatory mechanism of cell survival and death associated with the modulation of cell-substrate interactions. In fact, integrinmediated attachment to the extracellular matrix promotes cell survival (Boudreau et al, 1995; Brooks et al, 1994; Frish and Francis, 1994; Meredith et al, 1993; Montgomery et al, 1994). On the other hand, lack of adhesion leads to anoikia and the acquisition of anoikia resistance could facilitate anchorage-independent growth and, perhaps, transformation (Frisch et al, 1996). Zhang et al. (1995) first showed that integrin $\alpha 5 \beta 1$ binding to fibronectin was especially efficient at preventing the death of cells in serum-free medium. The crucial role was played by the $\alpha 5$ cytoplasmic domain possibly by regulating the expression of the cell death suppressor Bcl-2 (Zhang et al, 1995). Ligation of integrin $\alpha 5 \beta 1$ in $\alpha 5$-transfected tumor cells which exhibit reduced proliferation as compared with untransfected cells, also prevented apoptosis by inducing $\mathrm{Bcl}-2$ expression (Stromblad et al, 1996). Ligation of integrin $\alpha \mathrm{v} \beta 3$ in endothelial cells suppresses p53 activity and increases the Bcl-2:Bax ratio, promoting cell survival (Clarke et al, 1995; Stromblad et al, 1996). In contrast, blocking integrin $\alpha v \beta 3$ ligation with integrin antagonists induced p53 activation and blocked Bcl-2 expression (Stromblad et al, 1996). Thus, in these cell types, ligands to integrins have been shown partially to suppress the apoptotic cell death program. As concerns CNF1, we have recently reported that the toxin can increase the expression of $\mathrm{Bcl}-2$ and $\mathrm{Bcl}-$ $X_{L}$ in epithelial cells (Fiorentini et al, 1998b), findings which are consistent with the augmented expression of $\alpha 5$ and $\alpha \mathrm{V}$ (and possibly $\alpha 6$ ) that we have measured by flow cytometry in CNF1-treated cells. Moreover, since the growth matrix did not influence the destiny of cells exposed to the toxin (data not shown), we speculate that, accordingly to other reports (Zhang et al, 1995; Levkau et al, 1998), it is probably the activity of integrins as signal transducers in the cytosol more than the link to ECM which drives cells towards survival or death. The direct activation of Rho in cells by CNF1, which in turn increases the expression of anti-apoptotic proteins, may perhaps allow cells to overcome the need for a specific substrate for growth.

Interactions of integrins with extracellular matrix proteins can activate integrin signal transducers such as the focal adhesion kinase (FAK), which participates in the control of anchorage dependence. FAK can regulate apoptosis in normal epithelial and endothelial cells and the conferral of resistance to anoikia may suffice to transform certain epithelial cells (Frish et al, 1996, Levkau et al, 1998). In this study, we have observed that CNF1 increases the expression of FAK. Interestingly, CNF1 has previously been shown to induce a Rho-dependent tyrosine phosphorylation of FAK (Lacerda et al, 1997). How can FAK mediate the integrin-dependent survival signals? One possibility is that FAK, upon activation by CNF1, in turn activates the mitogen-activated protein (MAP) kinase through the RasRaf pathway (Schlaepfer et al, 1994). Interestingly, MAP kinase activation has been reported to suppress apoptosis (Xia et al, 1995).

Beside the phosphorylation of FAK (Lacerda et al, 1997), CNF1-promoted Rho activation induced contractility and cell spreading (Fiorentini et al, 1997a) as well as the polymerization of actin into prominent stress fibers, probably via activation of a cytoskeleton-associated phosphatidylinositol 4-phosphate 5-kinase (Fiorentini et al, 1997a; Burridge et al, 1997). Cell spreading is a phenomenon which is driven by forces deriving from actin polymerization (Theriot and Mitchison, 1991) and by actinmyosin-based forces (Cramer and Mitchison, 1995). Cell adhesion to extracellular matrix proteins is responsible for cell spreading through integrin receptors which promotes integrin clustering and cytoskeletal organization and forces cells to spread (Hynes, 1992). It is current opinion that cell spreading induced by integrin ligation, and the subsequent intracellular signaling, are needed to avoid apoptosis (Re et al, 1994, Ruoslahti, 1997) and that attachment per se does not prevent cell death (Ruoslahti and Reed, 1994). This is because the ability of anchorage-dependent cells to proliferate is mainly linked to the cell spreading and not to the attachment (Ruoslahti, 1997). We have to underline that, at least in our system, cell spreading per se was not enough to circumvent the apoptotic response. In fact, the flattening (spreading) provoked by certain doses of $C B$ in epithelial cells, was inefficient in triggering cell survival. 
Thus, in order to thrive, cells need additive factors which, in case of the CNF1-induced cell response, may be represented by the actin assembly into prominent stress fibers and, overall, by the Rho activity as controller.

The hypothesis of Rho as 'supervisor' of cell survival or death is now supported by several lines of evidence. Rho plays a selective role in early thymic development as a critical determinant for proliferation and cell survival signals, its inactivation by $C$. botulinum $\mathrm{C} 3$ leading to apoptosis (Henning et al, 1997). Inactivation of Rho proteins has also been reported to induce apoptosis in murine $\mathrm{T}$ lymphoma cells (Moorman et al, 1996) and GDI, an abundant cell GDP-dissociation inhibitor for the Ras-related Rho family GTPases, is a substrate of the apoptosis protease CPP32/ Caspase 3 ( $\mathrm{Na}$ et al, 1996). Moreover, bacterial protein toxins inhibiting the activity of proteins of the Rho subfamily may induce apoptosis in intestinal cells (Fiorentini et al, 1993; 1998a). Consistent with these findings which indicate that inactivation of Rho is a negative signal for survival, is our observation that CNF1, which activates Rho, protects epithelial cells from apoptosis (Fiorentini et al, 1997b). Very recently, a direct link between the functional state of Rho and $\mathrm{Bcl}-2$ expression in controlling the apoptotic pathway has also been suggested (Fiorentini et al, 1998b; Gomez et al, 1997).

Taking our results together with data previously reported (for a review see Meredith and Schwartz, 1997), promotion of Rho-dependent cell spreading and actin bundling results in protection against apoptosis. Thus, we propose CNF1 as a new and extremely useful tool for studying the relationships between apoptosis and the cytoskeleton. Not all data herein reported, however, can be directly referred to cytoskeletal modulation and several questions remain unanswered. For instance, it remains to be clarified why CNF1 decreases the expression of ICAM-1 and how this can be involved in apoptosis protection. Speculatively, since ICAM-1 is a molecule which binds leukocyte-specific surface antigens (Malik and Lo, 1996), the lack of interaction between CNF1-altered cells and immune cells might protect the former from being removed. This might allow the survival of damaged cells and their entry into the cell cycle, thus avoiding apoptosis. On the other hand, we have also to remember that CNF1 is a toxin produced by intestinal bacteria and that apoptosis is critical for maintaining the integrity of intestinal epithelium. As intestinal stem cells ascend upward from basement membrane along the crypt-villous axis toward the intestinal lumen, cellular differentiation and proliferative arrest do occur. Having reached the villi surface, cells become fully differentiated, undergo apoptosis and are shed in the lumen. Factors capable of prolonging cell survival could influence the integrity and function of the intestinal mucosa. Prolonged cell survival, together with increased adhesion to matrix components might have significant biological consequences and affect the tumorigenic potential of epithelial cells as previously reported (Tsujii and DuBois, 1995). Thus, considering the role of CNF1 in human pathology (Caprioli et al, 1987; Cherifi et al, 1990; De Rycke et al, 1990) apoptosis may turn out as being a new virulence mechanism for CNF1-producing bacteria.

\section{Materials and Methods}

\section{Cell cultures}

HEp-2 cells were grown at $37^{\circ} \mathrm{C}$ in DMEM medium, supplemented with $10 \%$ fetal calf serum (FCS) (Flow Laboratories, Irvine, UK), $1 \%$ non-essential aminoacids, $5 \mathrm{mM}$ L-glutamine, penicillin (100 U ml) and streptomycin $(100 \mu \mathrm{g} \mathrm{ml}))$ in a $37^{\circ} \mathrm{C}$ incubator containing an atmosphere of $95 \%$ air and $5 \% \quad \mathrm{CO}_{2}$. The subcultures were serially propagated after harvesting with $10 \mathrm{mM}$ EDTA and $0.25 \%$ trypsin in phosphate buffer solution (PBS, $\mathrm{pH}$ 7.4).

\section{Treatments}

$10^{-10}$ M CNF1 (purified as previously described (Falzano et al, 1993) from the $E$ coli BM2-1 strain) or $0.5 \mu \mathrm{g} \mathrm{ml}$ cytochalasin B (CB, Sigma Chemical Co, St Louis, MO) were directly added to the culture medium at the same time of seeding. After different times (i.e. 1, 3, 6, 12, 24 and $48 \mathrm{~h}$ ) of toxin treatment, HEp-2 cells were exposed to different apoptotic inducers (UVB, Etoposide or serum starvation). Samples were then prepared for fluorescence and scanning electron microscopy or for flow cytometry. All the experiments were performed at least four times with triplicate samples for each point.

\section{Induction of apoptosis}

Three different apoptotic inducers have been used: (i) a physical agent; (ii) a chemical agent and (iii) the withdrawal of growth factors.

UVB exposure Control and CNF1-treated HEp-2 cells were exposed to UVB irradiation in phosphate-buffered saline (PBS) using a Philips TL $20 \mathrm{~W} / 12$ lamp localized in a sterile hood. The plastic Petri dishes containing the cells were placed without covers at the vertical distance of $10 \mathrm{~cm}$ from the centre of the tube to UVB. In order to eliminate UVC radiation, a Kodak filter (Kodacell TL 401) with an optical density of less than 0.4 for wavelengths below $285 \mathrm{~nm}$ was employed and was placed on the Petri dishes during exposure. In these conditions, the UVB radiant flux density to the cells was $2.2 \mathrm{Wm}^{-2}$, as verified by an Osram Centra UV meter. The filter used in our experiments has an optical density of 2.5 at $285 \mathrm{~nm}, 3$ at $280 \mathrm{~nm}$ and above 4 for wavelengths below $270 \mathrm{~nm}$. Therefore we can estimate that the contamination by UVC to cells does not exceed $0.003 \%$ of the total UVB. Twenty-four hours after the end of the UVB irradiation, control and treated cells were prepared for fluorescence and scanning electron microscopy or for flow cytometry.

Etoposide treatment Etoposide is an anticancer drug capable of inducing apoptosis in epithelial cells (Oberhammer et al, 1993). Fortyeight hours after cell seeding or CNF1 exposure, $200 \mu \mathrm{M}$ Etoposide (Sigma; stock solution $0.01 \mathrm{M}$ in ethanol) was added directly to the culture medium for $48 \mathrm{~h}$. Cells treated with an equal volume of ethanol were considered as control.

Serum starvation Forty-eight hours after seeding or CNF1 exposure, HEp-2 cells were completely deprived of the FCS contained in the growth medium and then further cultured for $48 \mathrm{~h}$.

To evaluate the percentage of apoptosis in adherent control and treated cells the chromatin dye Hoechst 33258 (Molecular Probes Inc, Or) was used. Quantitative evaluation of apoptotic cell death was performed by counting at least 500 cells at high magnification $(500 \times)$ in triplicate samples for each point as previously described (Malorni et al, 1994). The numbers reported were the mean values \pm standard deviation (S.D.) from the experiments repeated six times. 


\section{Adhesion assay}

Stock preparations of collagen I, vitronectin, fibronectin, laminin, hyaluronic acid or bovine serum albumin (BSA) were distributed in $60 \mathrm{~mm}$ diameter Petri dishes (Costar, Cambridge, MA, USA) at the final concentrations of $10 \mathrm{mg} \mathrm{cm}, 0.1 \mathrm{mg} \mathrm{cm}{ }^{3}, 5 \mathrm{mg} \mathrm{cm}^{3}, 2 \mathrm{mg} \mathrm{cm}$, $5 \mathrm{mg} \mathrm{cm}^{3}$ and $3 \%$, respectively. After $2 \mathrm{~h}$ at room temperature, the coated dishes were washed three times with PBS to remove nonimmobilized proteins. To saturate the remaining protein binding sites $2 \mathrm{ml}$ of PBS supplemented with $1 \%$ heat-denatured BSA were added and the plates were incubated at room temperature for $1 \mathrm{~h}$. The attachment assay was adapted from that described by Malorni et al, (1995).

Control and CNF1-treated cells $\left(5 \times 10^{4}\right)$ were suspended in $4 \mathrm{ml}$ DMEM containing $10 \%$ fetal calf serum, seeded into coated Petri dishes and incubated for $30 \mathrm{~min}$ at $37^{\circ} \mathrm{C}$. After incubation, the 'unattached' cells were removed and the 'attached' cells were harvested from the assay dishes using $10 \mathrm{mM}$ EDTA and $0.25 \%$ trypsin. Unattached and attached cells were counted by ZBI Coulter Counter.

Percentages of attachment were calculated as follows:

$$
\frac{\text { Counts in matrix fraction }}{\text { Counts in matrix fraction counts in supernatant }} \times 100
$$

The data obtained represent the average of measurements made on three dishes. All the experiments were repeated four times.

\section{Fluorescence microscopy}

HEp-2 cells were grown on $13 \mathrm{~mm}$-diameter glass coverslips in separate wells $\left(5 \times 10^{4}\right.$ cells/well) in a $37^{\circ} \mathrm{C}$ incubator containing an atmosphere of $95 \%$ air and $5 \% \mathrm{CO}_{2}$. Following toxin and UVB treatments, both control and treated cells were fixed with $3.7 \%$ formaldehyde in PBS with $2 \%$ bovine serum albumin (BSA), for $10 \mathrm{~min}$ at room temperature. After washing in the same buffer, cells were permeabilized with $0.5 \%$ Triton $X-100$ in PBS for 10 min at room temperature. To analyze the nuclei, cells were stained with Hoechst 33258 (Sigma, working dilution $1: 1000$ ) at $37^{\circ} \mathrm{C}$ for $30 \mathrm{~min}$. For F-actin detection, cells were stained with fluoresceinphalloidin (Sigma, working dilution $1: 500$ ) at $37^{\circ} \mathrm{C}$ for $30 \mathrm{~min}$. Finally, after washings, coverslips were mounted with glycerol-PBS $(2: 1)$ and analyzed with a Nikon Microphot fluorescence microscope.

\section{Scanning electron microscopy}

Control and treated cells were fixed with $2.5 \%$ glutaraldehyde in $0.1 \mathrm{M}$ cacodylate buffer ( $\mathrm{pH} 7.4)$ at room temperature for 20 min. Following post-fixation in $1 \% \mathrm{OsO}_{4}$ for $30 \mathrm{~min}$, cells were dehydrated through graded ethanols, critical point dried in $\mathrm{CO}_{2}$ and gold coated by sputtering. The samples were examined with a Cambridge 360 scanning electron microscope.

\section{Flow cytometry}

Detection of intracellular antigens Control and treated HEp-2 cells were pelleted, fixed in $70 \%$ ice-cold methanol, and washed twice with cold PBS. For the detection of focal adhesion kinase (FAK), Ecadherin, $\alpha$-catenin or $\beta$-catenin cells were stained with specific monoclonal antibodies (mAb) (Chemicon International, Inc., Temecule, CA) for $30 \mathrm{~min}$ at $4^{\circ} \mathrm{C}$. After washing, cells were incubated for $30 \mathrm{~min}$ at $37^{\circ} \mathrm{C}$ with FITC-labeled anti-mouse mAb (Sigma), washed and analyzed.
Determination of cell-surface molecules The membrane expression of ICAM-1 (CD54), CD44, $\alpha 1$ (CD49a), $\alpha 2$ (CD49b), $\alpha 3$ (CD49c), $\alpha 4$ (CD49d), $\alpha 5$ (CD49e), $\alpha 6$ (CD49f) and $\alpha v$ (CD51) was studied by incubating cells for $30 \mathrm{~min}$ at $4^{\circ} \mathrm{C}$ with specific monoclonal antibodies (Chemicon). After washings with ice-cold PBS containing $10 \mathrm{mM}$ $\mathrm{NaN}_{3}, 1 \%$ BSA (Sigma) and $0.002 \%$ EDTA, cells were incubated for $30 \mathrm{~min}$ at $4{ }^{\circ} \mathrm{C}$ with FITC-labeled anti-mouse mAb (Sigma), washed and immediately analyzed by a Hewlett Packard computer using the Lysys II software (Becton Dickinson, San José).

Cell cycle analysis Biparametric DNA/BrdU analysis was performed by using propidium iodide (PI; $40 \mu \mathrm{g} \mathrm{ml}$ ), Bromodeoxyuridine (BrdU; $20 \mu \mathrm{M}$ ) and mAb against BrdU (Chemicon) as previously reported by Vindelov and Christensen, 1990. The samples were then analyzed on a FACScan flow cytometer (Becton Dickinson) performing excitation at $488 \mathrm{~nm}$ and collecting FL1=green fluorescence (FITC-BrdU) at 515$540 \mathrm{~nm}$ and FL2=red fluorescence (PI-DNA) above $620 \mathrm{~nm}$. The percentage of cells in different phases of the cell cycle was determined by a Hewlett Packard computer using the Lysys II software (Becton Dickinson).

\section{Statistical analyses}

Values reported in Figures 2, 4 and 5 are given as the mean \pm S.D. Student $t$-test ('Statistics' program for Macintosh) for correlated samples was used. A $P$ value of less than 0.01 was considered significant. Concerning flow cytometry, the statistical significance of the values obtained, reported in Table 1, was calculated by using the Kolmogorov-Smirnov (K/S) test included in Lysys II software (Becton Dickinson). Asterisks in Table 1 indicate antigens which undergo significant quantitative variation after CNF1 treatment.

\section{Acknowledgements}

This work was partially supported by the Italian National Research Council (CNR), grants no. 97.04906.ST74 (to C.F.) and no. 97.04814.ST74 (to W.M.).

\section{References}

Aktories K(1997)Rho proteins: targets forbacterial toxins. Trends Microbiol. 5:282288

Boudreau N, Sympson CJ, Werb Z and Bissell MJ (1995) Suppression of ICE and apoptosis in mammary epithelial cells by extracellular matrix. Science 267:891893

Braga VM, Machesky LM, Hall A and Hotchin NA (1997) The small GTPases Rho and Rac are required for the establishment of cadherin-dependent cell-cell contacts. J. Cell. Biol. 137: 1421-1431

Brooks PC, Montgomery AMP, Rosenfeld M, Reisfeld RA, Hu T, Klier G and Chercsh DA (1994) Integrins $\alpha_{v} \beta_{3}$ antagonists promote tumor regression by inducing apoptosis of angiogenic blood vessels. Cell 79: 1157-1164

Burridge K, Chrzanowska-Wodnicka M and Zhong C (1997) Focal adhesion assembly. Trends Cell. Biol. 7: 342-347

Bursh W, Oberhammer F and Schulte-Hemann R (1992) Cell death by apoptosis and its protective role against disease. Trends Pharmacol Sci. 13:245-251

Caprioli A, Falbo V, Ruggeri FM, Baldassarri L, Bissichia R, Ippolito G, Romoli E and Donelli $G$ (1987) Cytotoxic necrotizing factor production by haemolytic strains of Escherichia coli causing extraintestinal infections. J. Clin. Microbiol. 25: $146-$ 149

Cherifi A, Contrepois M, Picard B, Goullet PH, De Rycke J, Fairbrother Jand Barnouin $J$ (1990) Factors and markers of virulence in Escherichia coli from human septicaemia. FEMS Microbiol. Lett. 70: 279-285 
Clarke AS, Lotz MM, Chao C and Mercurio AM (1995) Activation of the p21 pathway of growth arrest and apoptosis by the beta 4 integrin cytoplasmic domain. J. Biol. Chem. 270: 22673-22676

Cooper JA (1987) Effects of cytochalasin and phalloidin on cells. J. Cell. Biol. 105: $1473-1478$

Cramer LP and Mitchison TJ (1995) Myosin is involved in postmitotic cell spreading. J. Cell. Biol. 131: 179-189

De Rycke J, Gonzalez EA, Blanco J, Oswald E, Blanco M and Boivin R (1990) Evidence for two types of cytotoxic necrotizing factor in human and animal clinical isolates. J. Clin. Microbiol. 28: 694-699

Falzano L, Fiorentini C, Donelli G, Michel E, Kocks C, CossartP, Cabanié L, Oswald E and Boquet $P(1993)$ Induction of phagocytic behaviour in human epithelial cells by Escherichia coliCytotoxic Necrotizing Factor type 1. Mol. Microbiol. 9: 12471254

Fiorentini C, Donelli G, Matarrese P, Fabbri A, Paradisi S and Boquet P (1995) Escherichia coli cytotoxic necrotizing factor 1: evidence for induction of actin assembly by constitutive activation of the p21 Rho GTPase. Infect. Immun. 63: $3936-3944$

Fiorentini C, Donelli G, Nicotera P and Thelestam M (1993) Clostridium difficile Toxin A elicits $\mathrm{Ca}^{+}$-independent cytotoxic effects in cultured normal rat intestinal crypt cells. Infect. Immun. 61: 3988-3993

Fiorentini C, Fabbri A, Flatau G, Donelli G, Matarrese P, Lemichez E, Falzano L and Boquet $\mathrm{P}$ (1997a) Escherichia colicytotoxic necrotizing factor 1 (CNF1), a toxin that activates the Rho GTPase. J. Biol. Chem. 272: 19532-19537

Fiorentini C, Fabbri A, Matarrese P, Falzano L, Boquet P and Malorni W (1997b) Hinderance of apoptosis and phagocytic behaviour induced by $E$. colicytotoxic necrotizing factor 1 (CNF1): two related activities in epithelial cells. Biochem. Biophys. Res. Comm. 241: 341-346

Fiorentini C, Fabbri A, Falzano L, Fattorossi A, Matarrese P, Rivabene R and Donelli G (1998a) Clostridium difficile toxin B induces apoptosis in intestinal cultured cells. Infect. Immun. 66: 2660-2665.

Fiorentini C, Matarrese P, Straface E, Falzano L, Fabbri A, Donelli G, Cossarizza A, Boquet $P$ and Malorni W (1998b) Toxin-induced activation of Rho GTP-binding protein increases $\mathrm{Bcl}-2$ expression and influences mitochondrial homeostasis. Exp. Cell. Res. 241: in press.

Flatau G, Lemichez E, Gauthier M, Chardin P, Paris S, Fiorentini C and Boquet P (1997) Toxin-induced activation of the $G$ protein p21 Rho by deamidation of glutamine. Nature 387: 729-733

Frisch SMand Francis H (1994) Disruption of epithelial cell-matrix interactions induce apoptosis. J. Cell. Biol. 124:619-626

Frisch SM, Vuori K, Ruoslahti E and Chan-Hui PY (1996) Control of adhesiondependent cell survival by focal adhesion kinase. J. Cell. Biol. 134: 793-799

Frisch SM (1997) Integrins and anoikis. Curr. Opin. Cell. Biol. 9: 701-706

Gomez J, Martinez C, Giry M, Garcia A and Rebollo A (1997) Rho prevents apoptosis through Bcl-2 expression: implication for interleukin 2-receptor signal transduction. Eur. J. Immunol. 27: 2793-2799

Guadagno TM, Ohtsubo M, Roberts JM and Assoian RK (1993) A link between cyclin A expression and adhesion-dependent cell cycle progression. Science 262: $1572-1575$

Hall A (1998) Rho GTPases and the actin cytoskeleton. Science 279: 509-514

Henning SW, Galandrini R, Hall A and Cantrell DA (1997) The GTPase Rho has a critical regulatory role in thymus development. EMBO J. 16: 2397-2407

Huber O, Bierkamp C, Kemler R (1996) Cadherins and catenins in development. Curr. Opin. Cell. Biol. 8: 685-691

Hynes R (1992) Integrins: versatility, modulation and signaling in cell adhesion. Cell 69: $11-25$

Kroemer G (1997) The proto-oncogene $\mathrm{Bcl}-2$ and its role in regulating apoptosis. Nature Med. 3: 614-620

Lacerda HM, Pullinger GD, Lax AJ and Rozengurt E (1997) Cytotoxic necrotizing factor 1 from Escherichia coli and dermonecrotic toxin from Bordetella bronchiseptica induce p21 (rho)-dependent tyrosine phosphorylation of focal adhesion kinase and paxillin in Swiss 3T3 cells. J. Biol. Chem. 272: 9587-9596

Levkau B, Herren B, Koyama H, Ross R and Raines EW (1998) Caspase-mediated cleavage of focal adhesion kinase $\mathrm{pp}^{125} \mathrm{FAK}$ and disassembly of focal adhesions in human endothelial cell apoptosis. J. Exp. Med. 187: 579-586

Mahida YR, Makh S, Hyde S, Gray T and Borriello SP (1996) Effect of Clostridium difficile toxin A on human intestinal cells: induction of interleukin 8 production and apoptosis after cell detachment. Gut 39: 337-347
Malik AB and Lo SK (1996) Vascular endothelial adhesion molecules and tissue inflammation. Pharmacol Rev. 48: 213-229

Malorni W, Donelli G, Straface E, Santini MT, Paradisi S and Giacomoni PU (1994) Both UVA and UVB induce cytoskeleton-dependent surface blebbing in epidermoid cells. J. Photochem. Photobiol. 26: 265-270

Malorni W, Rivabene R and Matarrese P (1995) The antioxidant N-acetyl-cysteine protects cultured cells from menadione-induced cytopathology. Chem. Biol. Interact. 96: 113-123

Martins LM and Earnshow WC (1997) Apoptosis: alive and kicking in 1997. Trends Cell. Biol. 7: 111-114

Meredith JE Jr and Schwartz MA (1997) Integrins, adhesion and apoptosis. Trends Cell. Biol. 7: 146-150

Meredith JE Jr, Fazeli B and Schwartz MA (1993) The extracellular matrix as a cell survival factor. Mol. Biol. Cell. 4: 953-961

Moorman JP, Bobak DA and Hahn CS (1996) Inactivation of the small GTP binding protein Rho induces multinucleate cell formation and apoptosis in murine $T$ lymphoma EL4. J. Immunol. 156: 4146-4153

Montgomery AMP, Reisfeld RA and Cheresh DA (1994) Integrin $\alpha v \beta 3$ rescues melanoma from apoptosis in a three-dimensional dermal collagen. Proc. Natl. Acad. Sci. 91: 8856-8860

Na S, Chuang T, Cunningham A, Turi TG, Hanke JH, Bokoch GM and Danley DE (1996) D4-GDI, a substrate of CPP32, is proteolyzed during Fas-induced apoptosis. J. Biol. Chem. 271: 11209-11213

Nobes C and Hall A (1995) Rho, Rac and CdC42 GTPases regulate the assembly of multimolecular focal complexes associated with actin stress fibers, lamellipodia and filopodia. Cell 81: 53-62

OberhammerF, Wilson JW, Dive C, Morris ID, Hickman JA, Walkeling EE, Walker PR and Sikorska M (1993) Apototic death in epithelial cells: cleavage of DNA to 300 and/or $50 \mathrm{~Kb}$ fragments prior to or in the absence of internucleosomal fragmentation. EMBO J. 12: 3679-3684

Re F, Zanetti A, Sironi M, Polentarutti N, Lanfrancone L, Dejana E and Colotta F (1994) Inhibition of anchorage-dependent cell spreading triggers apoptosis in cultured human endothelial cells. J. Cell. Biol. 127: 537-546

Ruoslahti E and Reed JC (1994) Anchorage dependence, integrins, and apoptosis. Cell 77: $477-478$

Ruoslahti $E$ (1997) Stretching is good for a cell. Science 276: 1345-1346

Schlaepfer DD, Hanks SK, Hunter T and van der Geer P (1994) Integrin-mediated signal transduction linked to Ras pathway by GRB2 binding to focal adhesion kinase. Nature 372: 786-791

Schmidt G, Sehr P, Wilm M, Jorg S, Mann M and Aktories K (1997) Glu 63 of Rho is deamidated by Escherichia colicytotoxic necrotizing factor-1. Nature 387: 725 729

Straface E, Santini MT, Donelli G, Giacomoni PU and Malorni W (1995) Vitamin E prevents UVB-induced cell blebbing and cell death in A431 epidermoid cells. Int J. Radiat. Biol. 68: 579-587

Stromblad S, Becker JC, Yebra M, Brooks PC and Cheresh DA (1996) Suppression of p53 activity and 21 WAF1/CIP1 expression by vascular cell integrin alpha $V$ beta 3 during angiogenesis. J. Clin. Invest. 98: 426-433

TheriotJA and Mitchison TJ (1991) Actin microfilament dynamics in locomoting cells. Nature 352: $126-131$

Tsujii M and DuBois RN (1995) Alterations in cellular adhesion and apoptosis in epithelial cells overexpressing prostaglandin endoperoxide synthase 2. Cell 83 : 493-501

Vindelov LLand Christensen IC (1990) A review of techniques and results obtained in one laboratory by an integrated system of methods designed for routine clinical cytometric DNA analysis. Cytometry 11: 753-758

Xia Z, Dickens M, Raingeaud J, Davis Rj and Greenberg ME (1995) Opposing effects of ERK and JNK-p38 MAP kinases on apoptosis. Science 270: 1326-1331

Yamada KM and Geiger B (1997) Molecular interactions in cell adhesion complexes. Curr. Opin. Cell. Biol. 9: 76-85

ZhangZ, VuoriK, ReedJC and Ruoslahti E (1995) The $\alpha 5 \beta 1$ integrin supports survival of cells on fibronectin and up-regulates Bcl-2 expression. Proc. Natl. Acad. Sci. USA 92: 6161-6165 